\title{
UNIDADE E DIVERSIDADE NA ANTIGUIDADE TARDIA: A ATUAÇÃO DO IMPERADOR TEODÓSIO II NA CONTROVÉRSIA EM TORNO DA NATUREZA DO CORPO DE CRISTO ENTRE CIRILO DE ALEXANDRIA E NESTÓRIO DE CONSTANTINOPLA (428-450 D.C.)
}

\author{
UNITY AND DIVERSITY IN THE LATE ANTIQUITY: THE \\ PERFORMANCE OF THE EMPEROR THEODOSIUS II IN THE \\ CONTROVERSY AROUND THE NATURE OF CHRIST'S BODY \\ BETWEEN CYRIL OF ALEXANDRIA AND NESTORIUS OF \\ CONSTANTINOPLE (428-450 A.D.)
}

Daniel de FIGUEIREDO•

Resumo: Esse artigo analisa a atuação do imperador Teodósio II (408-450) no conflito teológico que emergiu durante o seu governo e ficou conhecido pela historiografia como Controvérsia Nestoriana. Tal conflito foi protagonizado pelos bispos Cirilo de Alexandria e Nestório de Constantinopla, que divergiam acerca do relacionamento estabelecido entre as naturezas divina e humana do Cristo encarnado. Uma vez que formulações teológicas dessa natureza, na Antiguidade Tardia, serviam de suporte para formulações ideológicas de sustentação e unidade do poder imperial, pretendemos destacar o papel de centralidade do imperador como mediador desse conflito.

Palavras-chave: Antiguidade Tardia - Conflito político-religioso-administrativo - Controvérsia Nestoriana.

Abstract: This article analyzes the performance of the Emperor Theodosius II (408-450) at the theological conflict that emerged during his government and got notorious by historiography as Nestorian Controversy. Such a conflict was led by the bishops Cyril of Alexandria and Nestorius of Constantinople, who diverged about the relationship established between the divine and human natures of the incarnate Christ. Since theological formulations of such nature were used in Late Antiquity to support ideological formulations of sustaining and unity of the imperial power, we aim to highlight the role of centrality of the Emperor as a mediator in this conflict.

Keywords: Late Antiquity - Political, religious and administrative Conflict - Nestorian Controversy.

\section{Introdução}

O conflito teológico a que se refere o título desse artigo veio a ser conhecido pela historiografia como Controvérsia Nestoriana ${ }^{1}$ e tratou-se de um embate entre os bispos Cirilo de Alexandria e Nestório de Constantinopla, que divergiam acerca do

\footnotetext{
- Mestre em História - Programa de Pós-graduação em História - Faculdade de Ciências Humanas e Sociais - UNESP - Univ. Estadual Paulista, Campus de Franca, CEP: 14409-160, Franca, São Paulo Brasil. E-mail: $\underline{\text { d.fig@ @ol.com.br }}$
} 
relacionamento entre as naturezas divina e humana do Cristo encarnado. Tal querela teve início na primeira metade do século $\mathrm{V}$ d.C., durante o governo do imperador Teodósio II $^{2}$, no Império Romano do Oriente. Como nos indicou Ramsey MacMullen (2003, p. 486), uma disputa eclesiástica na Antiguidade Tardia ${ }^{3}$ pode ser comparada ao epicentro de uma grande tempestade, cuja imensa quantidade de energia despendida originava ondas que se propagavam a longas distâncias. No caso da Controvérsia Nestoriana, a sua emergência coincide com o início do episcopado de Nestório em Constantinopla, no ano de 428, e as discussões em torno dessas diferenças teológicas dividiram a hierarquia eclesiástica ortodoxa ${ }^{4}$, tanto no Império do Oriente quanto do Ocidente, já separados administrativamente. Esse embate também atraiu o envolvimento de funcionários da administração imperial e levou o imperador Teodósio II a intervir no sentido de mediar aquela disputa. Observamos que tais divergências ainda permeavam os debates na chamada Controvérsia dos Três Capítulos ${ }^{5}$, ocorrida no governo do imperador Justiniano (527-565) e durante o III Concílio Ecumênico de Constantinopla, em 680, ao fim do qual os argumentos de Cirilo prevaleceram sobre os de Nestório (DAVIS, 1983, p. 228-229; WICKHAM, 1983, p. xlv).

Os documentos em que podemos acompanhar a emergência e os desdobramentos desse conflito, durante o governo de Teodósio II (408-450), referem-se ao catálogo que elaboramos da correspondência epistolar de Cirilo, a obra Cinco Tomos Contra Nestório ${ }^{6}$, do mesmo bispo, e às memórias de Nestório expressas no seu Livro Heraclides $^{7}$. O conjunto das cartas cirilianas é composto de cento e quinze epístolas trocadas com seus pares da hierarquia eclesiástica ortodoxa, funcionários da administração imperial e o imperador Teodósio II, entre os anos de 428 e 444 . O Contra Nestório foi redigido no ano de 430, como resposta de Cirilo aos sermões proferidos por Nestório após a sua posse no episcopado de Constantinopla, em 428, e foi endereçado a membros da hierarquia eclesiástica e a funcionários imperiais (RUSSELL, 2000, p. 130131). As memórias que Nestório registrou do conflito no Livro Heraclides podem ser datadas entre os anos de 435 e 450, ou seja, o período que compreende o início do seu exílio, em decorrência da punição a ele infringida por, supostamente, ter atentado contra a divindade de Cristo, até sua morte em 450. Nessa obra, Nestório expõe e defende o seu ponto de vista doutrinal a partir da reprodução e refutação de várias cartas de Cirilo, de cartas de funcionários imperiais e do imperador. Logo, podemos colher aqui indicações acerca dos métodos utilizados pelos membros da hierarquia eclesiástica 
ortodoxa no sentido arregimentar partidários, envolver na querela funcionários da administração imperial e as ações tomadas pelo imperador durante o conflito.

\section{A Controvérsia Nestoriana e o seu contexto político-religioso}

As divergências doutrinais entre aqueles dois bispos, expressas nos documentos acima citados, não se resumiam a visões particulares de ambos acerca da natureza da divindade. Tratava-se de elaborações teológico-filosóficas enraizadas nas tradições alexandrina e antioquena ${ }^{8}$, das quais se faziam representantes, e que podem ser resumidas como se segue: Cirilo afirmava que, no momento da encarnação do Logos, a segunda pessoa da Trindade (GRILLMEIER, 1975, p. 272-273), teria ocorrido uma perfeita união das duas naturezas, a divina e a humana, no homem Jesus Cristo, de modo que se poderia falar em "uma natureza encarnada de Deus, a Palavra" (Cirilo, Contra Nestório, Tomo II, p. 41). Em consequência disso, seria pertinente manter o epíteto de Theotokos (Portadora de Deus) que a tradição havia atribuído à Virgem Maria. Nessa perspectiva, a preocupação do bispo alexandrino revestia-se de uma implicação soteriológica, ou seja, relacionada à salvação da humanidade. Para a tradição alexandrina, sobretudo aquela advogada pelo antecessor de Cirilo, o bispo Atanásio, a salvação estava centrada na comunicação das qualidades transcendentes da natureza divina com a humanidade, através da encarnação do Filho ou Logos. Desse modo, o Logos (a segunda Pessoa da Trindade) ao tomar a carne uniu-se à humanidade a fim de operar uma total transformação para a sua redenção, em vez de afetar o comportamento humano apenas através do ensino ou do exemplo (LYMAN, 2012, p. 93; BLAUDEAU, 2006, p. 1-4).

Nestório, de outro modo, buscava mostrar uma distinção entre essas naturezas, uma vez que parecia entender que a natureza divina de Cristo, coeterna com o Pai, não teria sido passível de sofrimento e tampouco teria sido gerada de uma mulher, ao contrário do que ocorrera à natureza humana do seu corpo. Para Nestório, portanto, seria mais adequado que a Virgem Maria fosse reconhecida como portadora da natureza humana de Cristo (Christotokos) (Nestório, Livro Heraclides, I, 1) ${ }^{9}$. Baseando-se nos ensinamentos dos bispos orientais ${ }^{10}$ Diodoro de Tarso e Teodoro de Mopsuéstia, a questão da Salvação para Nestório colocava-se de maneira diversa ao entendimento de Cirilo, pois ao propor apenas um vínculo, e não uma união, entre as naturezas humana e 
divina em Cristo ele operava, dessa forma, um distanciamento entre a divindade e a humanidade (BROWN, 2002, p. 97-104).

Verificamos que a existência de profundas diferenças entre esses dois projetos cristológicos rivais (BLAUDEAU, 2006, p. 1-22) e a complexidade que revestiu as discussões naquele momento ensejam, ainda hoje, dificuldades em interpretá-los por parte de teólogos e historiadores da Igreja. É comum encontrarmos trabalhos nessa perspectiva teológica ora questionando a ortodoxia de Cirilo, ora a heterodoxia de Nestório (BRAATEN, 1963, p. 252-253). Sendo assim, o nosso intento caminha em outra direção: entender a Controvérsia Nestoriana na perspectiva de um conflito político-religioso-administrativo, tanto no que se refere à relação entre os membros da hierarquia eclesiástica ortodoxa em construção e desta com o poder imperial, bem como à necessidade do imperador Teodósio II manter o conflito sob o seu controle, na medida em que definições teológicas dessa envergadura poderiam afetar as bases políticoreligiosas e administrativas sobre as quais se assentava o seu governo.
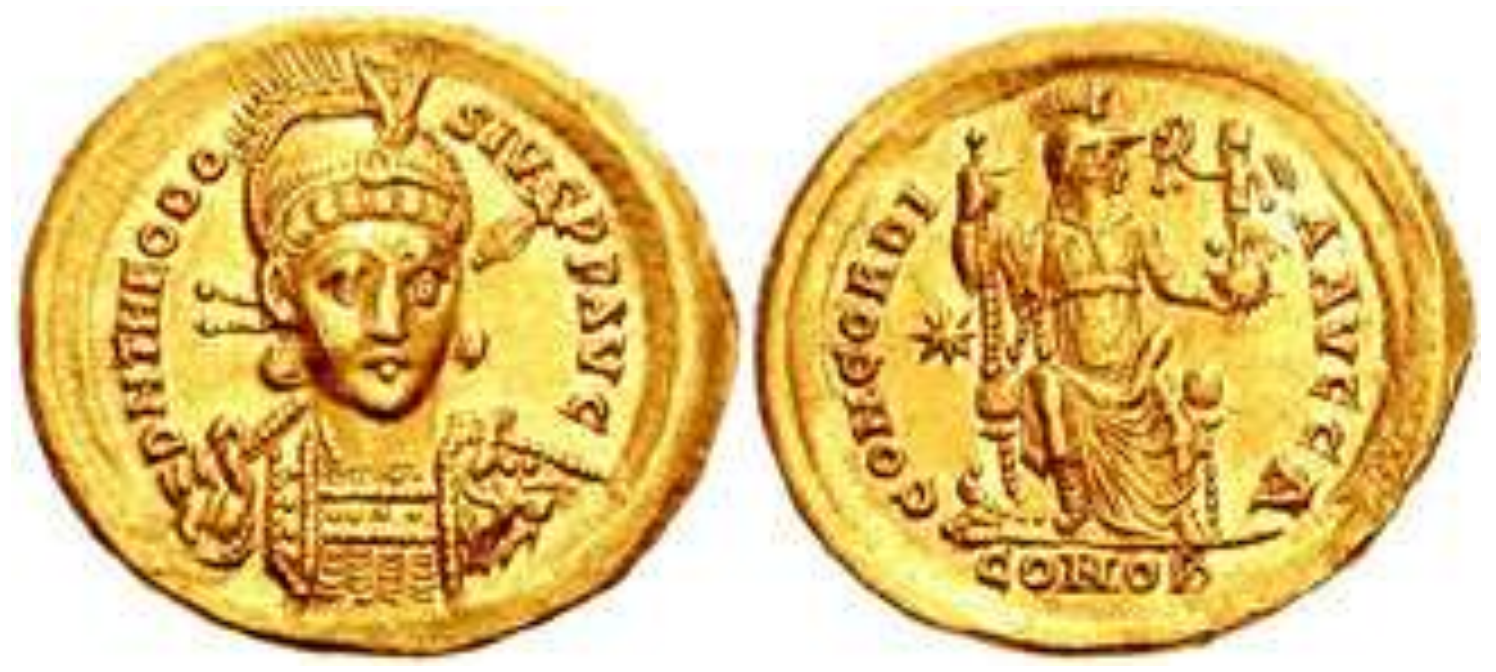

Fig. 1 - Solidus de Teodósio II (408-450)

AV solidus - RIC X, 202 (Constantinople) $^{11}$

Portanto, os conflitos que circundaram as tentativas de se afirmar um discurso cristão ortodoxo na Antiguidade Tardia não podem prescindir de uma análise que transcenda seus efeitos para além da esfera teológica em que emergiram. As fronteiras entre as manifestações de religiosidades no período, cristãs ou não cristãs, e as demais esferas da vida social, como a política, a cultura ${ }^{12}$, a administração e a economia, não 
eram nítidas. Um panorama desse ambiente nos é dado por Gilvan Ventura da Silva, que constata que:

[...] o sagrado se fixa numa dimensão supramundana, celeste e transcendente, cujo acesso é patrimônio de seres excepcionais ou com treinamento específico, como é o caso dos mártires, monges, bispos, filósofos, feiticeiros e adivinhos [...] não podendo absolutamente excluir desse repertório os próprios imperadores, que, do alto da dignidade que lhes foi conferida por determinação da própria divindade, se converterão em representantes por excelência do sagrado dentro da sociedade romana (SILVA, 2003, p.28).

Nessa atmosfera de religiosidades é que ocorre a aproximação da religião cristã com o poder político-cultural na Antiguidade Tardia. Esse encontro, que nas palavras de Paul Veyne (2009, p. 9) mostrou-se um dos acontecimentos mais decisivos na história ocidental, possibilitou ao discurso cristão desenvolver as suas formulações doutrinais na forma de uma teologia política ${ }^{13}$ como força legitimadora da unidade do Império Romano e da natureza do poder imperial (CARVALHO, 2010, p. 78-79). Em contrapartida, tal aproximação também contribuiu para a hierarquia eclesiástica ortodoxa se institucionalizar como uma organização formal baseada nos moldes da estrutura administrativa imperial. Contribuiu, também, para que seus líderes, os bispos cristãos, fossem absorvidos dentro da máquina imperial de recompensas e punições (HUNT, 2008, p. 240-249). Dessa forma, pode-se constatar que, a partir do século IV d.C., iniciando no governo do imperador Constantino, os Concílios Episcopais, que se tratavam de encontros de bispos para discutir, dentre outros assuntos, questões teológicas com o objetivo de legitimar determinadas interpretações das Escrituras Sagradas, passaram a ter uma ligação cada vez maior com o poder central. Essa disposição, portanto, poderia refletir a preocupação dos imperadores em resguardar uma unidade na fé, pois uma divisão nela poderia insinuar uma divisão na própria sociedade (CARVALHO, 2006, p. 272; PAPA, 2009, p. 28-29).

Historiadores eclesiásticos tardo-antigos, algumas vezes, buscaram retratar o aprofundamento desses laços entre o Estado romano e aquela forma de cristianismo dita ortodoxa, em determinado momento, de maneira natural e determinista. Eusébio de Cesareia (aprox. 265-339) (História Eclesiástica, X, 9.1), considerado o "pai da história da Igreja", afirma-nos que "a este [Constantino], por conseguinte, foi que Deus outorgou desde cima, como fruto digno de sua piedade, o troféu da vitória contra os ímpios". Ao interpretar os eventos da história dentro de um sistema ordenado, em que a 
sucessão dos acontecimentos históricos seria regida sob os auspícios de Deus e, portanto, inscrita dentro da história da salvação, Eusébio, de forma triunfante, parece imbuído do espírito de um inevitável Império "cristianizado" de cima para baixo. Essa idealização concebia um império que seria edificado em torno de uma igreja monolítica e universal, tendo o príncipe como protetor e os bispos, sucessores dos apóstolos, encarregados de manter a tradição apostólica da pureza doutrinária (WINKELMANN, 2003, p. 18-25).

Contudo, buscar uma uniformidade de ideias, dentro dessa extensa e complexa sociedade, permeada de interesses diversos, que garantisse uma relação harmoniosa e triunfante entre a política e a religião mostrou-se uma frágil noção, resultando em múltiplos conflitos entre os membros do clero e na relação deles com o poder imperial.

Isso pode ser constatado no transcorrer do século IV d.C., através da emergência de diversos conflitos nessas relações, que, embora de natureza teológica, estavam, contudo, atrelados aos interesses de legitimação da política religiosa imperial e às relações de poder, prestígio e autoridade dentro da hierarquia eclesiástica. Dentre as querelas que parecem ter sido mais significativas nesse século, em vista dos documentos preservados, estão aquelas conhecidas por Controvérsias Trinitárias, que se originaram em torno de certas definições que os textos das Escrituras Sagradas não haviam deixado explícitos, relacionadas, sobretudo, ao ser de Cristo, ou seja, a unidade do Deus criador e salvador (MONDONI, 2001, p. 121).

Sobre essas controvérsias, Miguel Spinelli (2002, p. 16) destaca que para dar aspectos de racionalidade a uma doutrina que fosse aceita pelos intelectuais da época, os primeiros helenistas convertidos ao Cristianismo mesclaram às razões filosóficas do saber helênico os princípios religiosos cristãos. Logo, essas definições sobre a relação entre as "pessoas" divinas despertavam conflitos na medida em que determinado grupo cristão buscava apropriar conceitos e doutrinas a partir de diferentes tradições filosóficas e, muitas vezes, ressignificava-os em benefício das suas próprias convicções ou interesses. Richard Lim (2001, p. 201-202) complementa que contribuiu para acirrar e perpetuar esses conflitos o apoio dos imperadores do momento a uma determinada formulação teológica, de acordo com as suas próprias expectativas, acrescida da patronagem imperial ${ }^{14}$ em favor de determinada facção episcopal. Desse modo, na Antiguidade Tardia essas relações entre o sagrado e as estruturas terrenas perpetuavam 
tensões entre imperium e sacerdotium, que teriam permeado as definições dos papéis recíprocos tanto dos imperadores quanto dos bispos (TESTA, 2009, p. 526).

Imperium e sacerdotium: o poder imperial em ação.

No século V d.C., as cartas de Cirilo e as memórias de Nestório constituem um rico material que nos demonstra que as disputas em torno dessas ideias teológicas poderiam estar relacionadas à busca por poder e autoridade, devido às posições e às tomadas de posição que os diferentes atores tomam nas suas relações dentro da esfera religiosa. Para reforçar a autoridade de um ponto de vista e de uma posição é que esses atores competem e essa competição tem implicações mais amplas, uma vez que mobiliza pessoas, delimita fronteiras, cria precedentes e estende a esfera de influências das lideranças. Portanto, conforme constatou Pierre Bourdieu (2007, p. 62-64), a esfera teológica é um lugar de concorrência e as ideologias produzidas nela visando à instauração de um monopólio dos instrumentos de salvação estão propensas a serem utilizadas em outras lutas em busca de poder e autoridade pelos seus membros.

Podemos constatar essa disposição através da análise da atuação de Teodósio II nesse conflito em que os bispos Cirilo e Nestório foram protagonistas. Nota-se tanto nos discursos de Cirilo quanto nos de Nestório que ambos atribuem ao imperador uma constante preocupação com a unidade da fé e, por consequência, com a unidade da Igreja. Essa predisposição de ambos os bispos de tentar coincidir as suas expectativas como se fossem aquelas do imperador alertou-nos sobre o caráter propagandístico de tais discursos, como representações de uma realidade que é construída no interesse de quem as cria e veicula (CHARTIER, 2002, p. 17-19). Na carta $\mathrm{n}^{\circ} 71$, endereçada por Cirilo a Teodósio II, temos essa indicação:

(3) É necessário que esse trabalho [empreendido por Cirilo contra as idéias nestorianas] chegue aos seus, piedosos e amorosos em Cristo, ouvidos, desde que, dentre outras boas coisas, isso também é uma parte da sua tranquilidade, que você escolheu, sem cessar, ser deliciada pelas palavras sobre a verdadeira fé $\left(\operatorname{Carta~}^{\circ} 71\right.$, de Cirilo a Teodósio II, destaque nosso).

Já na carta $n^{\circ} 5$, endereçada por Nestório a Cirilo, o então bispo da capital imperial segue na mesma linha de preocupação: 
(10) Pois os assuntos da Igreja diariamente seguem adiante e o número de fiéis tem aumentado, para a graça daqueles que tem contemplado as multidões e veem [nisso] se repetir as palavras do profeta: "A terra se encherá com o conhecimento do Senhor, como muita água cobrirá os mares". Uma vez que esse ensino tem derramado sua luz sobre os interesses do imperador e, para colocar brevemente, seria muita alegria encontrá-lo, dia-a-dia, cumprido entre nós esse famoso ditado em relação a todas as ímpias heresias e o correto ensinamento da Igreja (Carta $\mathrm{n}^{\circ} 5$, de Nestório para Cirilo, destaque nosso).

Durante o seu governo, Teodósio II convocou dois grandes Concílios Episcopais na tentativa de mediar as disputas entre as facções ciriliana e nestoriana: o Concílio de Éfeso I, em 431, e o Concílio de Éfeso II, em 449. Nota-se em ambos a efetiva participação de funcionários da administração imperial intermediando as negociações entre os bispos e as tentativas destes em cooptar esses funcionários aos seus projetos político-religiosos, seja por meio de artifícios retóricos ou mesmo pela farta distribuição de presentes, mecanismo comum no período para se obter acesso às instâncias de poder (Carta $n^{\circ} 96$ e Apêndice $n^{\circ}$ 4). O que percebemos através dessas iniciativas de ambas as facções foi o extravasamento do conflito para dentro da própria Corte Imperial. A forma aparentemente ambígua com que o imperador gerenciou essa situação é marcada pela historiografia, muitas vezes, como uma deficiência de Teodósio II na condução da política eclesiástica. Henri Chadwick (1993, p. 196), dentre outros na mesma linha ${ }^{15}$, afirma-nos que "como um cata-vento, a política da Igreja do imperador tendia a vacilar, dependendo se ele estava sendo controlado pela sua esposa [Eudóxia] ou pela sua irmã [Pulquéria]". Ao divergirmos desses entendimentos, passamos a expor a nossa interpretação, a partir da leitura dos documentos à nossa disposição acerca da atuação do imperador Teodósio II na querela.

A percepção que atribui a Teodósio II uma deficiência inata na condução dos negócios do Império Romano do Oriente tem encontrado amparo nas atitudes de Teodósio II de ora favorecer uma, ou outra facção em confronto. Após o momentâneo triunfo de Cirilo de Alexandria no Concílio de Éfeso I, em 431, que foi seguido de uma reação virulenta dos bispos nestorianos ao que ali fora decidido, recrudescendo o conflito, Teodósio II mobilizou altos funcionários imperiais no sentido de mediar um acordo entre as partes. Através da carta $\mathrm{n}^{\circ} 35$, escrita por Cirilo ao bispo João de Antioquia $^{16}$, o representante das ideias nestorianas no momento, podemos tomar conhecimento dessas ações do imperador: 
(1) As igrejas estão sendo dilaceradas pelo desacordo e é justo que todos estejam mais preocupados com essa situação. A fim de que elas possam ser unidas e cada discordância seja removida do nosso meio e porque o reverendíssimo em Deus e amado em Cristo imperador decretou que isso dever ser provocado. E, por essas razões, ele enviou o admirável tribuno e secretário Aristolau, aprouve a nós, para a remoção de toda a luta e para o bem de arbitrar a paz entre as igrejas de Deus, concordar com o voto do santo Concílio realizado contra Nestório, assegurá-lo como deposto, anatematizar os seus infames ensinamentos, porque as igrejas conosco têm sempre guardado a verdadeira fé irrepreensível, assim como suas santidades sempre guardou-a e a transmite ao povo (Carta $\mathrm{n}^{\circ} 35$, de João de Antioquia para Cirilo, Sisto e Maximiano).

Por meio de intensas negociações, conduzidas por agentes do imperador, Cirilo de Alexandria e João de Antioquia são compelidos a assinar, em 433, um documento que ficou conhecido como Fórmula da Reunião. Nele, Cirilo abranda a sua doutrina sobre a união hipostática das naturezas divina e humana, declarando agora que:

(1) Assim reconhecemos nosso Senhor Jesus Cristo, o unigênito Filho de Deus, ser perfeito Deus e perfeito homem feito de alma dotada de razão e de corpo, gerado do Pai antes dos tempos em relação a sua divindade e o mesmo nasceu da Virgem Maria de acordo com a sua humanidade, em dias recentes para a nossa salvação, consubstancial com o Pai na sua divindade e consubstancial conosco na sua humanidade. A união das naturezas foi efetuada, portanto nós confessamos um Cristo, um Filho, um Senhor. Em virtude desse entendimento da união que não envolve fusão, reconhecemos a Virgem Santa como Theotokos, porque Deus a Palavra foi 'feita carne' e 'tornou-se homem' e unindo-se no templo que tomou dela como resultado da sua concepção. Quanto aos termos usados sobre o Senhor nos escritos dos Evangelhos e apostólicos, nós reconhecemos que os teólogos trataram alguns como compartilhados porque eles se referiam a uma pessoa, alguns se referiam a duas naturezas separadamente, tradicionalmente ensinando a aplicação dos termos divinos para a divindade de Cristo e os termos humildes para a sua humanidade (Carta n 39 , de Cirilo para João de Antioquia. Destaques nossos e do autor).

A contrapartida exigida do bispo João de Antioquia ao recuo da posição de Cirilo foi aceitar a excomunhão e a deposição de Nestório:

(3) Mas, desde que ele [bispo Paulo de Emesa] não veio com um documento afirmando que João [de Antioquia] anatematizava Nestório, [...] eu disse que não era possível assegurar comunhão com ele, até que ele fizesse essas coisas. Mas, desde que vi que eles estavam bastante apáticos em relação a isso, e que o piedoso bispo Paulo não pensava muito bem sobre isso, assim como o meu senhor 
magnífico Aristolau também. Contudo, de modo que não podemos declinar a paz, adiando em muito a questão, nós escrevemos as cartas de comunhão. Um documento foi ditado, também, em acordo com o piedoso bispo Paulo, que o bispo de Antioquia [João] deve assinar, também. E eu enviei [para Antioquia] dois clérigos, juntos com o admirável Aristolau, com a condição que, se João subscrever a deposição de Nestório e anatematizar os seus ensinamentos, eles dariam as [minhas] cartas de comunhão. Caso contrário, eles deveriam retê-las. O admirável Aristolau, sob juramento, disse que os documentos não seriam entregues. Ele disse, se João não desejar assinar: "Eu navegarei em linha reta até Constantinopla e comunicarei ao reverendíssimo imperador que nada está no caminho da paz em relação à igreja de Alexandria, mas o bispo da igreja de Antioquia é quem não ama a paz" (Carta $n^{\circ} 37$, de Cirilo para Teognosto, Charmosino e Leôntio).

Na sequência desses acontecimentos, as cartas também nos mostram a situação de fragilidade tanto de Cirilo quanto João de Antioquia perante os seus respectivos aliados (Cartas $\mathrm{n}^{\circ} 42,45,46,53,54,55,57,58,59,61,62,64,65$ e 83). Cirilo veio a sofrer acusações de falta de firmeza em sua fé, cedendo em uma questão doutrinal que não poderia ser objeto de negociação. Já o bispo João de Antioquia viu a sua autoridade ser contestada pelos seus aliados em virtude de ter confirmado a excomunhão e a deposição de Nestório. Apesar do infortúnio a que Nestório foi relegado, ou seja, a excomunhão e o exílio, é notória a atuação do imperador, através dos seus prepostos, de favorecer, naquele momento, a cristologia nestoriana das duas naturezas em Cristo, em detrimento da união delas advogada por Cirilo e seus seguidores.

A controvérsia não encontra seu termo nesse estágio. A questão volta ao centro dos debates durante o Concílio de Éfeso II, em 449. Desta vez encontramos os funcionários imperiais destacados para acompanhar essa reunião operando agora de forma aberta em favor das ideias cirilianas, nesse momento capitaneadas e aprofundadas por Dióscoro de Alexandria, sucessor de Cirilo, e o monge Êutiques, arquimandrita de Constantinopla, que saem do Concílio consagrados como modelo de ortodoxia a ser seguido:

E Eusébio acusou-o [Êutiques] daquelas coisas perante Flaviano ${ }^{17}[\ldots]$ e [Êutiques] continuou dando mostras da sua impiedade, confessando que o corpo de Cristo não era consubstancial conosco, como se [não resultando] em duas naturezas, mas em uma natureza. Isso mexeu com o imperador, que não queria que ele [Êutiques] fosse afastado por deposição, mas ele não foi ouvido. Ele [imperador], portanto, preparou todas as coisas para a deposição de Flaviano e para a restauração de Êutiques (Nestório, Livro Heraclides, Livro II.2) ${ }^{18}$. 
O catálogo das cartas cirilianas por nós elaborado, os Cinco Tomos Contra Nestório e as memórias de Nestório no Livro Heraclides nos mostram que o envolvimento de Teodósio II na administração dos negócios eclesiásticos é marcante. Não se trata de um mero coadjuvante levado ao sabor das redes de influências. Em um importante estudo, Fergus Millar (2006, p. 168) observa que as penalidades impostas pelo imperador a determinados membros das facções em disputa foram brandas, em comparação a outros períodos em que o braço secular foi manejado para assegurar a unidade doutrinária, mas, ao invés disso, Teodósio II teria optado pela "ferocidade retórica". Esse historiador, tomando por base os discursos de Cirilo e Nestório, credita tal fato à preocupação do imperador com a saúde doutrinária e a unidade da Igreja. Também analisando a atuação de Teodósio II no conflito, Susan Wessel (2001, p. 301) acredita que:

\begin{abstract}
Enquanto Teodósio entendeu as questões teológicas em jogo na controvérsia, ele pode não ter entendido todas as sutilezas teológicas que estavam no cerne do desentendimento. Ele pode ter sinceramente acreditado que o ensino da natureza dual da Encarnação, que tinha sido encontrado pelo Concílio de Éfeso I para dividir a natureza única de Cristo em duas pessoas, estava sendo revivido em Constantinopla por Flaviano e outros. Ademais, a sua aliança com Crisáfio ${ }^{19}$ talvez explique por que ele, assim como muitos monges, clérigos e pessoas leigas depois dele, estavam tão dispostos a apoiar a visão cristológica da natureza única de Dióscoro e Êutiques. Acreditando que o problema cristológico já havia sido resolvido pela Fórmula da Reunião, em 433, Teodósio pensou que o novo Concílio de Éfeso II (449) meramente confirmou as verdades lá estabelecidas [na Fórmula da Reunião]. Quando Leão o Grande ${ }^{20}$ tentou convencê-lo de outro modo, Teodósio declarou abertamente que ele estava protegendo a ortodoxia nicena $^{21}$ ao apoiar as decisões de Éfeso II. Apenas depois da morte de Teodósio, em 450, Leão foi capaz de efetivar as mudanças nas decisões daquele concílio.
\end{abstract}

Em nossa percepção, concordamos com Millar que não era desejo do imperador eliminar nem uma nem outra facção, mas entendemos que as suas ações foram no sentido de enfraquecer cirilianos e nestorianos. Ao dividir a hierarquia eclesiástica e tentar cooptar altos funcionários da Corte Imperial em torno das suas ideias, Cirilo e Nestório criaram um problema administrativo para o imperador, que poderia vir a perder o controle sobre os seus subordinados diretos, que desempenhavam o importante papel de ajudar a construir e sustentar o simbolismo que exteriorizava o seu poder e autoridade. Portanto, não podemos atribuir à atuação de Teodósio II no conflito apenas uma preocupação para assegurar a unidade da Igreja e nem considerar que as suas 
atitudes se relacionavam a certa ingenuidade em relação aos assuntos teológicos em jogo.

Ao conduzir o conflito na hierarquia eclesiástica de modo a perpetuar as tensões entre as facções ciriliana e nestoriana em disputa, não destruindo nenhuma das duas, mantinha-as sob controle. Ora favorecendo essa, ora aquela corrente doutrinária, Teodósio II freou, também, a emergência de uma facção ciriliana ou nestoriana forte no interior da administração imperial, que poderia vir a fazer sombra a sua autoridade e ameaçar os seus interesses de governante. Portanto, em nossa concepção, o discurso de "unidade da Igreja" atribuído a Teodósio II, pelo menos no que se refere às ideias cirilianas e nestorianas, era retórico. Manobrar a diversidade parece ter sido o grande trunfo do seu longo governo de quarenta e dois anos, no sentido de manter a unidade imperial.

\section{Referências Bibliográficas}

Fontes

CYRIL OF ALEXANDRIA. Letters 1-50. The Fathers of the Church. Vol. 76.

Translated by John I. McEnerney. Washington/DC: The Catholic University of Press, $2007 \mathrm{a}$.

Letters 51-110. The Fathers of the Church. Vol. 77. Translated by John I.

McEnerney. Washington/DC: The Catholic University of Press, 2007b.

Five Tomes Against Nestorius. Trad. E. B. Pusey. Oxford: James Parker and Co., and Rivingtons, 1881.

EUSÉBIO DE CESARÉIA. História Eclesisática. Tradução de Wolfgang Fischer. São Paulo: Fonte Editorial, 2005.

NESTORIUS. The Bazaar of Heracleides. Translated from the syriac by G. R. Driver and Leonard Hodgson. Oxford: Oxford University Press/Clarendon Press, 1925.

Le Livre d'Heraclide de Damas. Traduit en français par F. Nau avec le concours P. Bedjan et M. Briere. Paris: Letouzey et Ané Éditeurs, 1910.

Livros e periódicos

BEVAN, George A. The Case of Nestorius: Ecclesiastical politics in the East, 428-451

CE. Thesis (Degree of doctor of Philosophy. University of Toronto, 2005.

BLAUDEAU, Philippe. Alexandrie et Constantinople (451-491): de l'historie à la géoéclesiologie. Roma : École Française de Rome, 2006. 
BLOCKLEY, Roger C. The Dynasty of Theodosius. In: CAMERON, Averil; GARNSEY, Peter. (Org.). The late Empire, A.D. 337-425. The Cambridge Ancient History vol. XIII: Cambridge, UK: Cambridge University Press, 2008, p. 111-137. BOURDIEU, Pierre. A economia das trocas simbólicas. Tradução de vários tradutores. São Paulo: Perspectiva, 2007.

BRAATEN, Carl E. Modern interpretations of Nestorius. Church History, vol. 32, nr. 3. Published by: Cambridge University Press on behalf of the American Society of Church History, Sep. 1963, p. 251-267.

BROWN, Peter. Poverty and Leadership in the Later Roman Empire. Hanover/NH: University Press of New England, 2002.

CARVALHO, Margarida Maria. Gregório de Nazianzo e a polêmica em torno da restauração pagã de Juliano. In : SILVA, Gilvan Ventura da ; MENDES, Norma Musco. (Org.) Repensando o Império Romano : perspectiva socieconômica, política e cultural. Rio de Janeiro: Mauad, 2006, p. 267-284.

. Paidéia e retórica no séc. IV d.C.: a construção da imagem do Imperador Juliano segundo Gregório de Nazianzeno. São Paulo: Annablume, 2010.

CHADWICK, Henry. The early church: the story of emergent Christianity from the apostolic age to the dividing of the ways between the Greek East and the Latin West. 2 a. ed. London: Penguin Books, 1993.

CHARTIER, Roger. A história cultural: entre práticas e representações. 2. ed. Tradução de Maria Manuela Galhardo. Algés/Oeiras: Difel, 2002.

CHAUI, Marilena. O retorno do teológico-político. In: CARDOSO, Sérgio (Org.).

Retorno ao republicanismo. Belo Horizonte: Editora UFMG, 2004, p. 93-134.

DAVIS, Leo Donald. The first seven Ecumenical Councils (325-787): their history and theology. Collegeville, Minnesota: The Liturgical Press, 1983.

GEERTZ, Clifford. A interpretação das culturas. Tradução de LTC. Rio de Janeiro: Livros Técnicos e Científicos Editora S.A., 2008.

GRILLMEIER, Aloys. Christ in Christian Tradition: from the apostolic age to Chalcedon (451). Translated by John Bowden. Atlanta: John Knox Press, 1975. HUNT, David. The church as a public institution. In: : CAMERON, Averil; GARNSEY, Peter. (Org.). The late empire, AD 337-425: The Cambridge Ancient History, Vol. XIII. Cambridge/UK: Cambridge University Press, 2008, p. 238-276. JONES, Arnould Hugh Martin. The later roman empire, 284-602: A social, economic and administrative survey. 2 vol. Baltimore: Johns Hopkins University, 1964. KELLY, Christhopher. Patronage. In: BOWERSOCK, Glen Waren; BROWN, Peter; GRABAR, Oleg. (Org.). Late Antiquity: a guide to the postclassical world. Cambridge/MA: Harvard University Press, 1999b, p. 637-638.

LIM, Richard. Christian triumph and controversy. In: BOWERSOCK, Glen W.; BROWN, Peter; GRABAR, Oleg. (Org.). Interpreting late antiquity: essays on the postclassical world. Cambridge/MA: The Belknap Press of Harvard University Press, 2001, p. 196-218.

LYMAN, J. Rebecca. Christology and cosmology: models of divine activity in Origen, Eusebius and Athanasius. Oxford: Oxford Scholarship Online, 2011, p. 1-124. In: < http://www.oxfordscholarship.com.ezproxy.apollolibrary.com/view/10 $>$ Acesso em 23.01.2012.

MacMULLEN, Ramsey. Cultural and Political Changes in the 4th and 5th Centuries. In: Historia: Zeitschrift für Alte Geschichte, Vol. 52, nr. 4, 2003, p. 465-495.

MAGALHÃES, Júlio César. Arianistas. In: FUNARI, Pedro Paulo A. (Org.). As religiões que o mundo esqueceu: como egípcios, gregos, celtas, astecas e outros povos cultuavam seus deuses. São Paulo: Contexto, 2009, p. 87-101. 
MARTINDALE, John Robert. The Prosopography of the later Roman Empire. AD 395527. Cambridge: Cambridge University Press, 1980.

MILLAR, Fergus. A Greek Roman Empire: Power and Belief under Theodosius II (408450). Los Angeles: California University Press, 2006.

MONDONI, Danilo. História da Igreja na Antiguidade. São Paulo: Edições Loyola, 2001.

OLIVEIRA, Júlio César Magalhães de. O conceito de Antiguidade Tardia e as transformações da cidade antiga: o caso da África do Norte. Campinas: Revista de E. F. e H. da Antiguidade, $\mathrm{n}^{\circ}$ 24, jul. 2007/jun. 2008, p. 125-137.

PAPA, Helena Amália. Cristianismo ortodoxo versus cristianismo heterodoxo: uma análise político-religiosa da contenda entre Basílio de Cesareia e Eunômio de Cízico (Séc.: IV d.C.). Dissertação (Mestrado em História). FHDSS/UNESP, Campus Franca, 2009.

RUSSELL, Norman. Cyril of Alexandria. London: Routledge, 2000.

SILVA, Gilvan Ventura da. Reis, santos e feiticeiros: Constâncio II e os fundamentos místicos da Basiléia (337-361). Vitória: Edufes, 2003.

SPINELLI, Miguel. Helenização e recriação de sentidos: a filosofia na época da expansão do cristianismo. Porto Alegre: EDIPUCRS, 2002.

TESTA, Rita Lizzi. The Late Antique Bishop: Image and reality. In: ROUSSEAU, Philip; RAITHEL, Jutta. (Orgs.). A Companion to Late Antiquity. Oxford/UK:

Blackwell Publishing Ltd., 2009, p. 525-538.

VEYNE, Paul. Quando o nosso mundo se tornou cristão. Tradução de Artur Morão. Lisboa: Texto e Grafia, 2009.

WACE, Henry; PIERCY, WILLIAN C. A Dictionary of Christian Biography and Literature to the End of the Sixth Century A.D., with an Account of the Principal Sects and Heresies. Grand Rapids, MI: Christian Classics Ethereal Library, 1999. WESSEL, Susan. The Ecclesiastical Policy of Theodosius II. In: Annuarium Historiae Conciliorum, $\mathrm{n}^{\circ}$ 33, 2001, p. 285-308.

WICKHAM, Lionel Ralph. Cyril of Alexandria: Select letters. Oxford: Clarendon Press, 1983.

WINKELMANN, Friedhelm. Historiography in the age of Constantine. In:

MARASCO, Gabriele. (Org.). Greek and roman historiography in late antiquity: fourth to sixth century AD. Leiden/Boston: Brill, 2003, p. 3-42.

Notas

\footnotetext{
${ }^{1}$ Ao que nos parece, o termo Controvérsia Nestoriana tratou-se de uma construção posterior àqueles eventos que marcaram as divergências entre Cirilo, Nestório e seus respectivos partidários. Os desdobramentos desse conflito foram longos, de modo que utilizaremos essa denominação mesmo para incluir aqueles eventos ocorridos após a deposição do bispo Nestório.

${ }^{2}$ Governou o Império Romano do Oriente entre os anos de 408 e 450, após a morte do seu pai, o imperador Arcádio. Contava com apenas sete anos de idade na ocasião da sua ascensão ao poder. Morreu em julho de 450, em decorrência de uma queda acidental do seu cavalo. Foi sucedido pelo imperador Marciano, general que se casou com sua irmã, a Augusta Pulquéria (MARTINDALE, 1980, p. 1100).

3 O período entre os séculos III e VIII d.C., conhecido pelos especialistas por Antiguidade Tardia, é caracterizado por rupturas, permanências e transformações em relação aos valores clássicos, como, por exemplo, a emergência de novas concepções ideológicas relacionadas ao Cristianismo. Julio César M. Oliveira (2007/2008, p. 135) considera o período como a "última" Antiguidade que, embora seja dotado de características próprias, ainda conserva formas antigas. A despeito de uma maior preponderância de trabalhos historiográficos com ênfase nos aspectos culturais, Oliveira advoga que "nenhuma interpretação de conjunto das transformações do período deveria prescindir de uma abordagem global que leve em
} 
conta não só as ideias, mas também a materialidade da existência e as condições de vida da maioria da população".

${ }^{4}$ O imperador Teodósio I, em 380, oficializou como ortodoxa uma das diferentes formas de cristianismos, que foi referendada pelo Concílio de Constantinopla, em 381, e colocou na ilegalidade os demais grupos que passaram a ser considerados heréticos, como os arianos e os eunomianos. Cabe lembrar que a ortodoxia alcançada nesse momento trata-se daquela consagrada pelo Concílio de Nicéia, com poucas diferenças, em 325, a qual, utilizando-se de um vocabulário muito comum aos filósofos neoplatônicos da época, postulava o compartilhamento da mesma natureza entre o Pai, o Filho e o Espírito Santo, ou seja, uma mesma entidade manifestando-se em três substratos distintos (uma ousia e três hipostasis) (MAGALHÃES, 2009, p. 99).

${ }^{5}$ Essa controvérsia resultou na anatematização das obras dos bispos Teodoro de Mopsuéstia, Teodoreto de Ciro e Ibas de Edessa, que foram consideradas nestorianas (DAVIS, 1983, p. 207-257).

${ }^{6}$ Segundo Norman Russell (2000, p. 131), o Contra Nestório parece não ter circulado amplamente. Contudo, cópias dele teriam sido mantidas por Cirilo para distribuí-las quando a ocasião demandasse. Tem-se registro, através do próprio Cirilo, de dois destinatários dessa obra: o Praepositus Sacri Cubiculi do Oriente Crisero e o bispo Sucenso de Diocesaréia.

${ }^{7}$ Um estudo sobre a preservação dos escritos de Nestório pode ser obtido em BEVAN, 2005, p. 18-29.

${ }^{8}$ Refere-se à cidade de Antioquia, capital da Diocese do Oriente, que hoje se localiza na região que corresponde à Síria.

${ }^{9}$ Livro Heraclides, ed. Driver \& Hodgson, p. 8-9 e ed. F. Nau, p. 6-7.

${ }^{10}$ Como "bispos orientais", referimo-nos àqueles que exerciam os seus episcopados nas cidades localizadas na Diocese do Oriente, composta por diversas províncias e cuja capital era a cidade de Antioquia. A diocese do Oriente, junto com as dioceses do Egito, Asiana, Pôntica e Trácia, estavam reunidas numa circunscrição administrativa maior denominada de Prefeitura Pretoriana do Oriente (JONES, 1964, p. 373).

${ }^{11}$ Imagem de caráter ilustrativo. Disponível em:

$<$ http://www.ancientcoins.ca/RIC/RIC10/RIC10_TheodosiusIIE.htm>. Acesso: Mai./2013.

${ }^{12}$ A religião conforme definida por Clifford Geertz (2008, p. 65-91) constitui "um sistema de símbolos que atua para estabelecer poderosas, penetrantes e duradouras disposições e motivações nos homens através da formulação de conceitos de uma ordem de existência geral e vestindo essas concepções com tal aura de fatualidade que as disposições e motivações parecem singularmente realistas". O autor pressupõe que a religião corresponde a um dentre outros numerosos constituintes que, quando tomados juntos, constitui uma "cultura".

${ }^{13}$ Entende-se teologia como a busca por explicações sobre o ser de Deus e o sentido do mundo, a partir de revelações divinas. De acordo com Marilena Chauí (2004, p. 119), a teologia trata-se de um sistema de imagens que busca o reconhecimento da autoridade do teólogo (e não da verdade intrínseca de sua interpretação) e, ao mesmo tempo, a submissão dos que o escuta, que será tanto maior se for conseguida por consentimento interior. A teologia, portanto, é política porque ao operar com preceitos de justiça e caridade interfere em conflitos sociais, podendo colocar obstáculos à obtenção da paz, da segurança e da liberdade dos cidadãos. Embora Chauí formule esse conceito a partir da leitura da obra do filósofo Espinosa (1632-1677), julgamos adequado adotá-lo, também, para a Antiguidade Tardia.

${ }^{14} \mathrm{~A}$ sociedade da Antiguidade Tardia estava significativamente conformada por uma complexa rede de relacionamentos pessoais entre patronos e clientes. Esses laços, que se estabeleciam entre indivíduos de diferentes status sociais, eram importantes fatores na alocação de recursos políticos e econômicos, na indicação em ofícios (civil, militar ou eclesiástico) e na obtenção de acesso a ou proteção de indivíduos que detinham poder (KELLY, 1999, p. 637-638). Os imperadores, portanto, também estavam inseridos nessas redes.

${ }^{15}$ Vide também BLOCKLEY, 2008, p. 133-135.

${ }^{16} \mathrm{Na}$ Carta nr. 23, Cirilo nos indica que Nestório, antes de ser nomeado bispo de Constantinopla, esteve subordinado ao bispo João de Antioquia, que provavelmente o indicou ao imperador Teodósio II para ocupar o episcopado da capital imperial.

${ }^{17}$ Flaviano era o bispo de Constantinopla que apoiava as duas naturezas em Cristo, conforme defendido por Nestório.

${ }^{18}$ Livro Heraclides, ed. Driver \& Hodgson, p. 340 e ed. F. Nau, p. 298.

${ }^{19}$ Eunuco spatharius na Corte Oriental entre 443-450. Era monofisista e compartilhava a visão do monge Êutiques sobre a unidade das naturezas em Cristo (MARTINDALE, 1980, p. 295-296). 
${ }^{20}$ Bispo de Roma entre 440 e 461 . Atuou, através de prepostos, no Concílio de Éfeso II (449) em defesa do bispo Flaviano de Constantinopla e contra as ideias de Êutiques e Dióscoro de Alexandria (WACE, 1999, p. 1015-1047).

${ }^{21}$ A ortodoxia estabelecida pelo Concílio de Nicéia (325) afirmava o seguinte credo: "Cremos em um só Deus, Pai todo-poderoso, criador de todas as coisas visíveis e invisíveis, e em um só Senhor Jesus Cristo, Filho Único gerado pelo Pai, isto é, da substância do Pai, Deus nascido de Deus, luz nascida da luz, Deus verdadeiro, nascido de Deus verdadeiro, gerado, não criado, consubstancial ao Pai, por quem tudo foi feito no céu e na terra. Por nossa salvação... Quanto aos que dizem: houve um tempo em que Ele não era, ou: Ele não era antes de ser gerado, ou então: Ele saiu do nada, ou que o Filho de Deus é de outra substância ou essência, ou que Ele foi criado ou que Ele não é imutável, mas sujeito à mudança, a Igreja os anatemiza" (PAPA, 2009, p. 44).

Artigo recebido em10/05/2013. Aprovado em 20/06/2013. 